\title{
Influência da alteração da distribuição do tamanho de partículas no desempenho de reator UASB tratando esgoto doméstico
}

\section{Influence of alteration of particle size distribution on the performance of UASB reactor treating domestic wastewater}

\author{
Ana Raquel Teixeira \\ Doutora em Saneamento, Meio Ambiente e Recursos Hídricos pela Universidade Federal de Minas Gerais (UFMG) \\ Carlos Augusto de Lemos Chernicharo \\ Professor do Departamento de Engenharia Sanitária e Ambiental da UFMG \\ Tatiana Figueiredo da Silva Souto \\ Mestre em Saneamento, Meio Ambiente e Recursos Hídricos pela UFMG \\ Fernando Silva de Paula \\ Mestre em Saneamento, Meio Ambiente e Recursos Hídricos pela UFMG
}

\begin{abstract}
Resumo
O trabalho consistiu na avaliação do desempenho de um reator UASB tratando esgoto doméstico pré-tratado em uma unidade de peneiramento forçado (UPF), resultando na redução do tamanho médio de partículas da matéria orgânica afluente. Os experimentos foram conduzidos em dois reatores UASB em escala de demonstração idênticos, sendo um precedido da UPF e o outro utilizado como controle. Os resultados apontaram que, após a adaptação da biomassa às novas condições cinéticas e hidráulicas (reduzido TDH seguido de alta carga biológica aplicada), a redução do tamanho das partículas, na faixa de 1,8 a $30 \mu \mathrm{m}$, resultou na seleção de uma comunidade microbiana de maior atividade (atividade metanogênica específica de 0,072 g DQO/g STV.dia, quatro vezes superior à do reator controle). Isso propiciou um melhor desempenho do reator UASB precedido da UPF, o qual apresentou uma maior eficiência de remoção de $\mathrm{DQO}_{\text {TOTAL }}(65$ versus $54 \%$ no reator controle), e um efluente com menor DQO PARTICULADA $(48$ versus $74 \mathrm{mg} / \mathrm{L}$ no reator controle).
\end{abstract}

Palavras-chave: distribuição do tamanho de partículas; esgoto doméstico; peneiramento forçado; reator UASB; pré-tratamento.

\begin{abstract}
The work aimed at evaluating the performance of an UASB reactor treating domestic sewage pre-treated in a Forced Sieving Unit (FSU) which resulted in size reduction of the influent organic matter particles. The experiments were carried out in two identical demonstration-scale UASB reactors, one with a FSU upstream and the other used as control reactor. The results showed that, after biomass adaptation to new kinetic and hydraulic conditions (Iow hydraulic detention time followed by high sludge load), the particles size reduction, in the range of 1.8 to $30 \mu \mathrm{m}$, resulted in a microbial community selection with higher activity (specific methanogenic activity of $0.072 \mathrm{~g} \mathrm{COD} / \mathrm{g}$ VTS. day four times higher than in the control reactor). This enabled a better performance of the UASB reactor with the FSU, which showed a higher removal efficiency in terms of $\mathrm{COD}_{\text {TOTAL }}$ (65 versus $54 \%$ in the control reactor), and an effluent with lower concentration of $\mathrm{COD}_{\text {PATTICULATE }}$ (48 versus $74 \mathrm{mg} / \mathrm{L}$ in the control reactor).
\end{abstract}

Keywords: particles size distribution; domestic sewage; forced sieving; UASB reactor; pre-treatment.

Endereço para correspondência: Carlos Augusto de Lemos Chernicharo - Departamento de Engenharia Sanitária e Ambiental da UFMG - Avenida do Contorno, 842, $7^{\circ}$ andar - Centro - CEP 30110-060 - Belo Horizonte (MG), Brasil - Tel.: (31) 3409-1020 - E-mail: calemos@desa.ufmg.br

Recebido: 4/3/08 - Aceito: 23/11/08 - Reg. ABES: 044/08 


\section{Introdução}

Os reatores anaeróbios de fluxo ascendente e manta de lodo (reatores UASB) representam um grande avanço na aplicação da tecnologia anaeróbia para tratamento direto de águas residuárias e se mostram de grande aplicabilidade devido às suas inúmeras vantagens, das quais se destacam: baixos custos de implantação e operação; simplicidade operacional; baixos requisitos de área; reduzido consumo de energia e boa eficiência na remoção da matéria orgânica carbonácea (VON SPERLING, 2005).

Todavia, um fato que pode limitar a digestão anaeróbia e reduzir a eficiência global do sistema de tratamento é a presença de material particulado no afluente. A matéria orgânica particulada pode contribuir significativamente para a demanda química de oxigênio (DQO) efluente de reatores UASB, e pode ser constituída tanto por biomassa arrastada do reator como por material particulado originalmente presente no afluente. Ainda que a maior parte da matéria orgânica particulada presente no esgoto bruto seja biodegradável, a degradação apenas parcial desse material pode ocorrer devido a vários fatores. A presença de caminhos preferenciais na manta de lodo do reator UASB caracterizaria um curtocircuito hidráulico, o que diminuiria o tempo de detenção hidráulica (TDH) e, consequentemente, o tempo de contato entre a biomassa e potenciais substratos. Ademais, a elevada presença de materiais particulados no afluente pode dificultar a hidrólise desses compostos limitando a degradação da matéria orgânica, uma vez que a hidrólise, etapa inicial da decomposição anaeróbia, ocorre, normalmente, de forma mais lenta que as reações subsequentes (VAVILIN; RYTOV; LOKSHINA, 1996). Elmitwalli (2001) afirma que, em reatores anaeróbios, as partículas são convertidas pela hidrólise depois de serem fisicamente removidas por adsorção, sedimentação ou aderidas ao leito de lodo. Consequentemente, são requeridos maiores TDHs para a completa solubilização da matéria orgânica em sistemas de tratamento de efluentes com elevadas concentrações de sólidos suspensos. De acordo com Aiyuk (2006), os sólidos suspensos podem diminuir a atividade da biomassa, no que tange à adsorção e interceptação, e limitar a transferência de substratos.

Portanto, a presença de material particulado no efluente dificulta $\mathrm{o}$ atendimento aos requisitos da legislação ambiental brasileira e, por isso, é importante conceber sistemas de tratamento que favoreçam a sua degradação em reatores anaeróbios. Assim, para evitar a deterioração da qualidade da biomassa e da sua consequência inerente, devido à quantidade elevada de DQO particulada contida nos efluentes, novas tecnologias são desenvolvidas, visando a alterar o tamanho das partículas presentes no afluente (remoção ou "quebra" de sólidos suspensos). A adoção de tais medidas, no entanto, implica custos adicionais como, por exemplo, energia, equipamentos, produtos químicos, manejo de lodo ou resíduos entre outros.

Cabe ressaltar que a distribuição do tamanho de partículas nos esgotos influencia também os aspectos físicos dos reatores, uma vez que a dimensão das partículas influencia as taxas de sedimentação, adsorção e difusão (LEVINE; TCHOBANOGLOUS; ASANO, 1985).
Por exemplo, nos tratamentos anaeróbios de alta taxa, a DQO coloidal dos esgotos domésticos é removida em taxas menores que sob condições aeróbias devido à baixa retenção física das partículas coloidais que, em tese, permanecem dentro dos reatores apenas pelo tempo equivalente ao tempo de detenção hidráulica (WANG; ZEEMAN; LETTINGA, 1995; ELMITWALLI, 2001).

Uma concepção inovadora testada no presente trabalho, objetivando a melhoria do desempenho e o aumento da eficiência de remoção de material particulado nos reatores UASB, consistiu em peneiramento forçado do esgoto bruto. Tal estratégia se baseia na hipótese de que a diminuição do tamanho médio de partículas da matéria orgânica afluente pode resultar em um aumento da taxa de hidrólise do material particulado e aumentar, consequentemente, as taxas das conversões metabólicas subsequentes. Portanto, o objetivo do trabalho foi avaliar o efeito da alteração do tamanho de partículas sobre o desempenho de reatores UASB tratando esgoto doméstico.

O projeto é um estudo detalhado de um sistema de tratamento adaptado à nossa realidade, ou seja, não utilizável nos países mais desenvolvidos e de clima temperado, e busca a otimização de uma tecnologia simplificada e de baixo custo que pode contribuir sobremaneira com a reversão do grave quadro sanitário existente no país.

\section{Material e métodos}

\section{Aparato experimental}

Para testar os eventuais benefícios do pré-tratamento do esgoto bruto na melhoria da eficiência do sistema de tratamento, foram concebidos dois reatores UASB geminados e idênticos, implantados, em escala de demonstração, no Centro de Pesquisa e Treinamento em Saneamento (CePTS) UFMG/Copasa construído junto à Estação de Tratamento de Efluente (ETE) Arrudas, em Belo Horizonte. As unidades foram alimentadas com esgoto doméstico afluente à ETE Arrudas, após ter passado pelas unidades de tratamento preliminar (gradeamento médio e desarenadores), através de linhas de sucção paralelas equipadas com bombas similares que permitiam a variação da vazão afluente ao reator. A unidade de peneiramento forçado (UPF), constituída por um toco flangeado na tubulação de recalque do qual era encaixada a peneira metálica, operava a montante de um dos reatores (reator R2), permitindo a análise comparativa com o reator controle (reator R1) conforme o fluxograma do aparato experimental apresentado na Figura 1. A peneira utilizada possuía aberturas de $1 \mathrm{~mm}$, dificultando a entrada de sólidos de maiores dimensões e resultando, assim, na diminuição no tamanho médio das partículas afluentes ao reator. As Figuras 2 e 3 apresentam, respectivamente, o desenho esquemático e a vista da unidade de peneiramento forçado.

Os dois módulos contíguos de reatores UASB, construídos em aço, com volume de $14 \mathrm{~m}^{3}$ e dimensões internas úteis de 1,75 x 1,75 


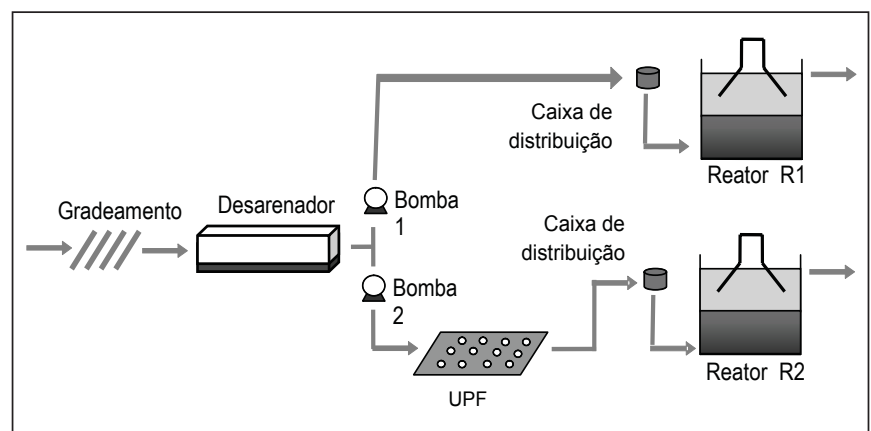

Figura 1 - Fluxograma do aparato experimental

x $6,0 \mathrm{~m}$, foram projetados com flexibilidade para testar diferentes alturas do reator (altura total útil) e diferentes configurações do compartimento de digestão

A operação do reator foi dividida em duas etapas, caracterizadas pelas diferentes seções transversais, e cada etapa, por sua vez, foi subdividida em três fases operacionais definidas em função das diferentes velocidades ascensionais e TDH, conforme mostra a Tabela 1. A fase 5 foi desmembrada em duas, a fim de se possibilitar a avaliação dos eventuais benefícios da utilização de meio suporte plástico no interior dos compartimentos de decantação dos reatores UASB (fase 5B). Os reatores assim constituídos foram denominados de reatores híbridos, uma vez que passaram a agregar uma característica de meio suporte comumente utilizada em filtros anaeróbios. O meio suporte utilizado consistiu em aparas de conduíte corrugado, com $3 \mathrm{~cm}$ de comprimento e 1" de diâmetro, dispostas aleatoriamente no compartimento de decantação dos reatores. Tal estratégia foi utilizada para avaliar a capacidade de remoção complementar da matéria orgânica através dos efeitos de filtração e decantação e da atuação do meio suporte.

Vale ressaltar que não foram simuladas variações horárias, mantendo a vazão constante durante toda a operação do sistema.

\section{Parâmetros de monitoramento dos efluentes}

O monitoramento do sistema envolveu as análises de DQO e SST, com frequência de duas vezes por semana e a partir de

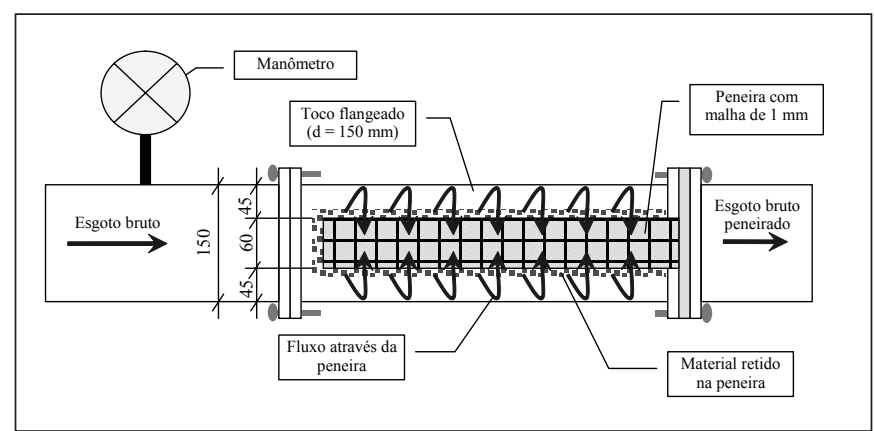

Figura 2 - Esquema da unidade de peneiramento forçado
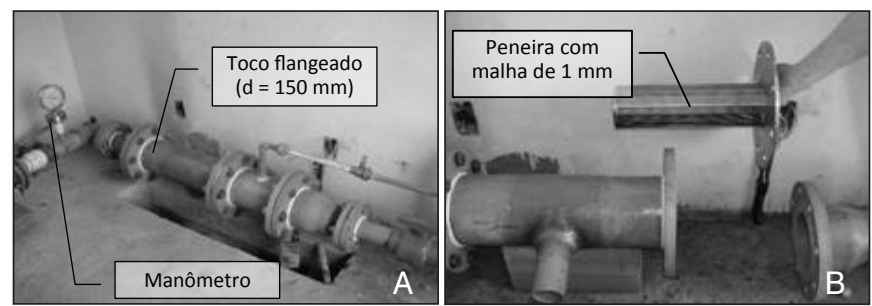

Figura 3 - Vista da unidade de peneiramento forçado; (A) manômetro e toco flangeado que contém a peneira; (B) peneira em aço inox

amostras compostas ao longo de 24 horas para os esgotos bruto e bruto peneirado, bem como para os efluentes dos dois reatores. Foram realizadas, quinzenalmente, análises de ST e STV no lodo dos reatores de amostras coletadas ao longo da altura dos mesmos $(0,05 ; 0,65 ; 1,10,1,60 ; 2,10 ; 2,60$ e 3,10 m). As análises foram feitas de acordo com os procedimentos descritos no Standard methods for the examination of water and wastewater (AWWA/APHA/ WEF, 1998).

\section{Testes de Atividade Metanogênica Específica (AME)}

As amostras de inóculo utilizadas no teste foram compostas pelo lodo retirado dos reatores nas alturas 0,05 e 0,65 m (duas torneiras de fundo). O teste foi realizado em frascos de vidro de $110 \mathrm{~mL}$, fechados por septos de borracha e lacres metálicos. Utilizou-se cola

Tabela 1 - Principais características dos reatores UASB e condições operacionais

\begin{tabular}{|c|c|c|c|c|c|c|}
\hline \multirow{2}{*}{ Características do reator e condições operacionais } & \multicolumn{3}{|c|}{ Etapa 1} & \multicolumn{3}{|c|}{ Etapa 2} \\
\hline & Fase 1 & Fase 2 & Fase 3 & Fase 4 & Fase $5 \mathrm{~A}$ & Fase $5 B^{*}$ \\
\hline Seção transversal (m) & \multicolumn{3}{|c|}{$1,75 \times 1,75$} & \multicolumn{3}{|c|}{$1,50 \times 1,50$} \\
\hline Área $\left(m^{2}\right)$ & \multicolumn{3}{|c|}{3,06} & \multicolumn{3}{|c|}{2,25} \\
\hline Área de influência do tubo de distribuição (m²) & \multicolumn{3}{|c|}{3,06} & \multicolumn{3}{|c|}{2,25} \\
\hline Altura útil (m) & 4,5 & 5,0 & 5,5 & 4,5 & 5,0 & 5,0 \\
\hline Volume útil (m³) & 13,8 & 15,3 & 16,8 & 10,1 & 11,3 & 11,3 \\
\hline Equivalente populacional (hab) & 308 & 442 & 675 & 226 & 322 & 322 \\
\hline Vazão média (L/s) & 0,43 & 0,61 & 0,94 & 0,31 & 0,45 & 0,45 \\
\hline TDH médio (horas) & 9,0 & 7,0 & 5,0 & 9,0 & 7,0 & 7,0 \\
\hline Velocidade ascensional (m/h) & 0,50 & 0,71 & 1,10 & 0,50 & 0,71 & 0,71 \\
\hline Duração (dias) & 70 & 64 & 53 & 77 & 91 & 103 \\
\hline
\end{tabular}

*Na fase 5B, foi inserido o meio suporte no compartimento de decantação (reator híbrido); TDH: tempo de detenção hidráulica. 
de silicone para a vedação dos frascos após a coleta do biogás. A agitação era geralmente orbital e contínua, realizada por uma incubadora/agitador, ajustada em $200 \mathrm{rpm}$ e temperatura a $30^{\circ} \mathrm{C}$. Para imposição de um ambiente anaeróbio, realizou-se a lavagem da atmosfera do frasco-reator com um gás inerte - uma mistura de nitrogênio e gás carbônico (70 e 30\%, respectivamente). Utilizou-se acetato (acetato de sódio) como única fonte de carbono e energia (concentração de $2 \mathrm{~g}$ acetato/L). O volume de biomassa foi variável, com a finalidade de se obter uma concentração de 0,5 g SV/L, resultando numa relação A/M igual a 4. Visando ao bom desenvolvimento da comunidade microbiana do lodo, foi acrescida uma solução de macro (fósforo, nitrogênio, ferro e enxofre) e micronutrientes (traços de metais) e fonte de alcalinidade. A produção do gás no interior do frasco gera um acréscimo de pressão, possibilitando a determinação do volume de biogás com o uso de uma seringa graduada de vidro esmerilhado umedecida para minimização da força de atrito entre o êmbolo e o corpo da seringa. Ao conectar a seringa ao frasco por meio de uma agulha a pressão interna do frasco iguala-se à pressão atmosférica (considerando-se o atrito entre êmbolo e seringa próximo a zero) - o volume de biogás produzido ocupa a seringa graduada, podendo, então, ser medido. Após a medição, a caracterização do biogás e quantificação do metano presente foi feita por cromatografia gasosa. O teste era interrompido quando a produção acumulada de metano tornava-se constante. A atividade metanogênica foi calculada a partir das taxas de produtividade máxima de metano (gDQO- $\mathrm{CH}_{4} / \mathrm{gSTV}$.dia).

\section{Análises estatísticas}

Visando comparar a igualdade da tendência central dos parâmetros analisados nos esgotos bruto e bruto peneirado, foram realizados testes de hipótese por meio do programa computacional Statistica, versão 6.1. O programa gera como resultado o valor de

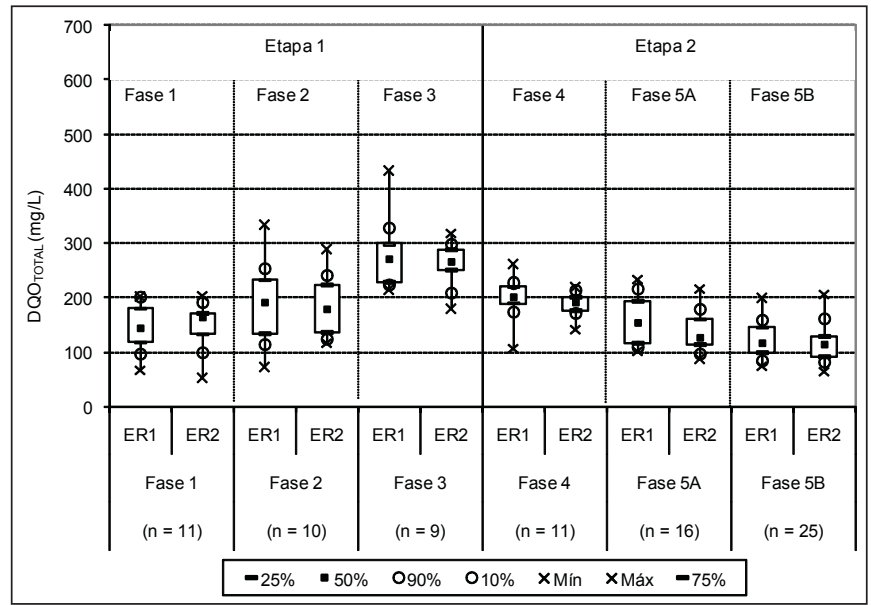

Figura 4 - Gráfico Box \& Whisker da DQ0 ${ }_{\text {TOTAL }}$ dos efluentes dos reatores controle (ER1) e precedido da UPF (ER2) $p$ que deve ser maior que (1- $\alpha)$, sendo $\alpha$ o intervalo de confiança, para que a hipótese seja aceita. Adotou-se o intervalo de confiança de $95 \%$.

Como não se pode garantir que as amostras sigam uma distribuição normal, associados ao pequeno número de dados disponibilizados, foram aplicados testes não-paramétricos, escolhidos conforme o conjunto amostral analisado. Para avaliar diferenças nas médias observadas entre dois grupos de amostras dependentes ou pareadas, que abrangem os resultados dos efluentes dos reatores, foi aplicado o teste $t$ de Wilcoxon.

O teste não-paramétrico de Kruskal-Wallis ANOVA e teste de medianas foram utilizados para se verificar a existência de diferenças significativas entre os resultados medianos obtidos nas diferentes fases operacionais. Quando os resultados obtidos são considerados diferentes pelos testes Kruskal-Wallis ANOVA e teste de medianas, podem ser empregados os testes de comparações múltiplas de classes para todos os grupos. Esses testes permitem uma comparação simultânea entre todos os resultados obtidos e a verificação de quais fases apresentaram desempenhos diferenciados.

\section{Resultados e discussão}

Os resultados obtidos por Teixeira (2005) mostram que, após a passagem do esgoto bruto pela peneira com malha de $1 \mathrm{~mm}$, houve um aumento da porcentagem de partículas com diâmetros entre 1,8 e $30 \mu \mathrm{m}$, e consequente diminuição da porcentagem de partículas com diâmetros maiores ( $50 \mu \mathrm{m})$, diferenciando os efluentes no que tange à distribuição de tamanho de partículas.

As Figuras 4 a 7 mostram os gráficos Box \& Whisker das concentrações efluentes total e filtrada de DQO e a eficiência de remoção dos reatores.

Da análise das Figuras 4 a 7, depreendem-se as seguintes considerações na comparação entre o desempenho dos reatores:

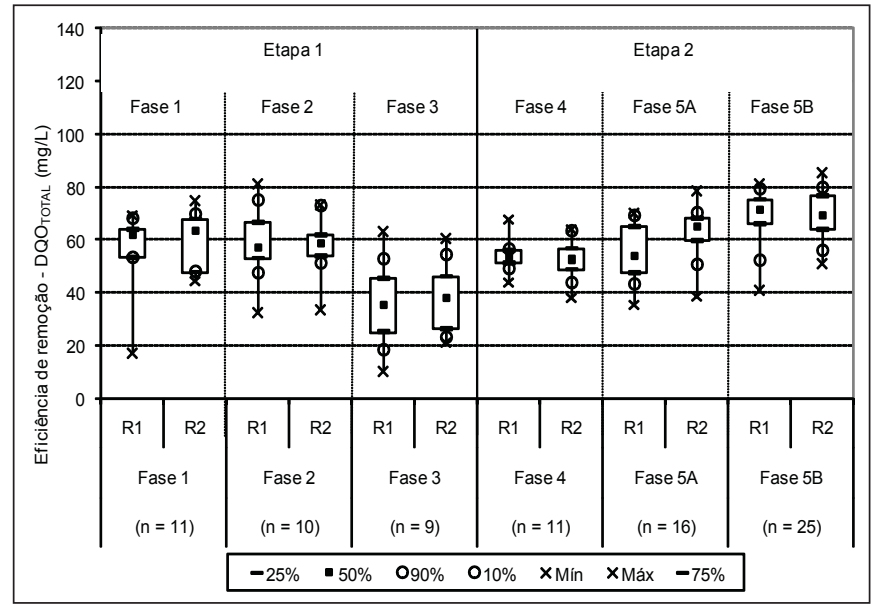

Figura 5 - Gráfico Box \& Whisker da eficiência de remoção de $\mathrm{DQO}_{\text {TOTAL }}$ dos reatores controle (R1) e precedido da UPF (R2) 


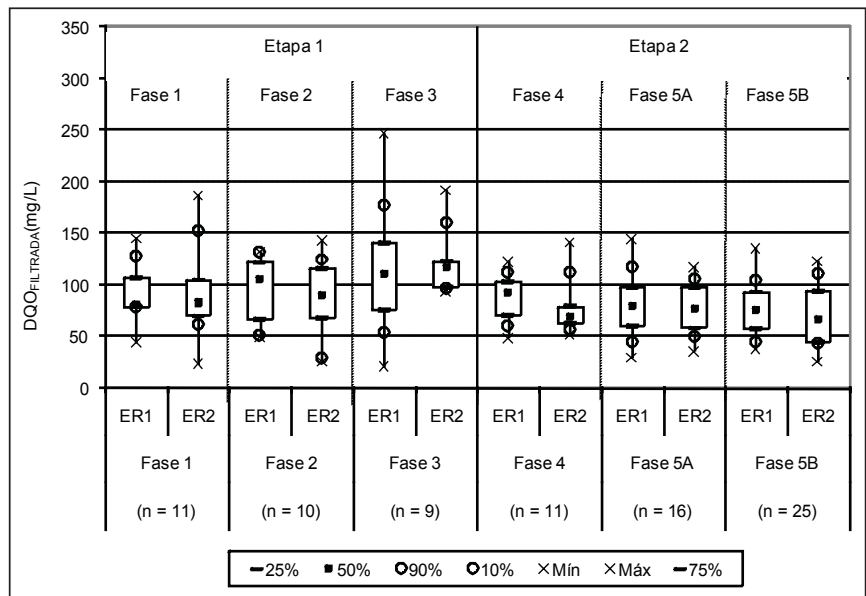

Figura 6 - Gráfico Box \& Whisker da DQO ${ }_{\text {FUTRADA }}$ dos efluentes dos reatores controle (ER1) e precedido da UPF (ER2)

- a mediana dos resultados de $\mathrm{DQO}_{\mathrm{TOTAL}}$ do reator precedido da UPF foi superior, na fase 1, à do reator controle. Porém, tal diferença não foi estatisticamente comprovada pelo teste $t$ de Wilcoxon. Os testes de hipótese, no entanto, negaram a igualdade dos dados dos efluentes, obtidos durante o monitoramento da fase $5 \mathrm{~A}$, indicando que a alteração da DTP do esgoto bruto pode resultar em menor $\mathrm{DQO}_{\text {TOTAL }}$ no efluente do reator UASB, operado com TDH de sete horas, velocidade ascensional de $0,71 \mathrm{~m} / \mathrm{h}$ e área de influência do tudo distribuidor de esgoto de $2,25 \mathrm{~m}^{2} /$ tubo. O mesmo se confirma, pela análise da Figura 5 e pelos testes estatísticos, que o reator precedido da UPF apresentou eficiência de remoção de $\mathrm{DQO}_{\text {TOTAL }}$ (65\%) superior à do reator controle (54\%) nessa fase operacional. Ressalta-se que os resultados obtidos durante a fase $5 \mathrm{~A}$ podem apresentar-se mais relevantes e confiáveis do que os das fases anteriores, uma vez que o período operacional dessa fase teve maior duração (91 dias). Com isso, possibilitou-se um maior tempo de recuperação da biomassa e, também, de sua adaptação às condições operacionais impostas. Ou seja, após expurgar os resultados transientes de início de operação da fase, ainda assim, foi obtido um maior conjunto de resultados durante o regime estacionário aparente, típicos das últimas semanas da fase. Além disso, as condições operacionais impostas pelas fases 3 e 4 , favoreceram a seleção e desenvolvimento de uma biomassa com maior atividade;

- a DQO ${ }_{\text {FILTRAda }}$ do efluente do reator precedido da UPF foi inferior à do reator controle nas fases 2,4 e $5 \mathrm{~B}$ e superior na fase 3 . Somente na fase 1 houve diferença da eficiência de remoção de DQO FILTRADA entre os reatores, sendo que o reator precedido da UPF mostrou melhor desempenho (80\%). Todavia, provavelmente devido ao número de dados e à alta variabilidade existente entre eles, os testes estatísticos efetuados não comprovam tais diferenças.

Quando se analisam as diferentes condições operacionais dos reatores, é possível fazer os seguintes comentários:

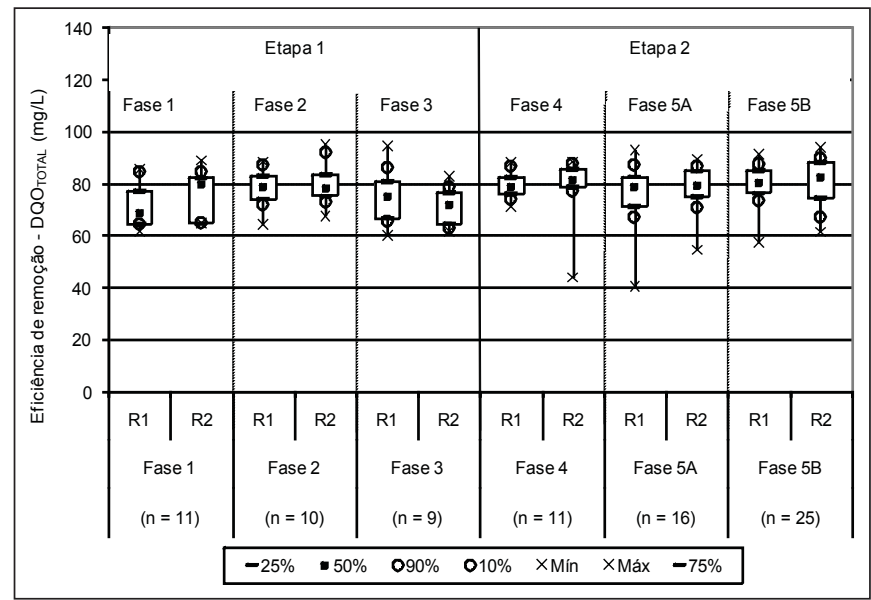

Figura 7 - Gráfico Box \& Whisker da eficiência de remoção de $D Q 0_{\text {FILTADA }}$ dos reatores controle (R1) e precedido da UPF (R2)

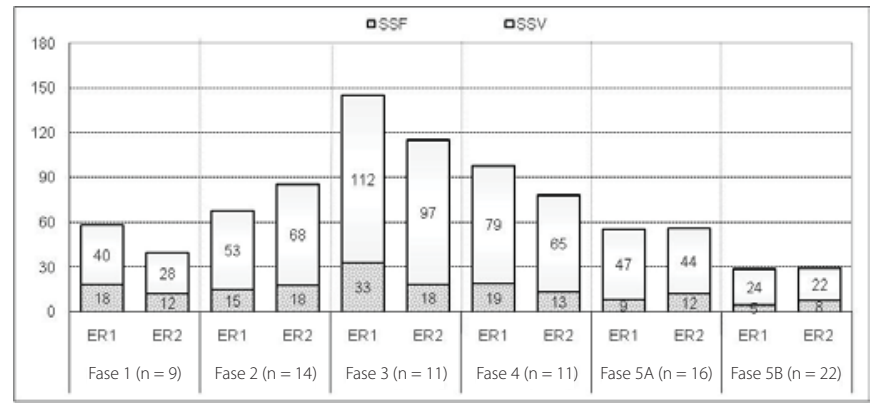

Figura 8 - Composição dos SST presentes nos efluentes dos reatores controle (ER1) e precedido da UPF (ER2)

- na etapa 1, a redução do TDH de nove para sete horas proporcionou um aumento na $\mathrm{DQO}_{\text {TOTAL }}$ média do efluente do reator (Figura 4) e consequente redução na eficiência de remoção (Figura 5). Porém, na etapa 2, aconteceu o inverso, indicando que o aumento na velocidade ascensional (de $0,50 \mathrm{~m} / \mathrm{h}$ para $0,71 \mathrm{~m} / \mathrm{h}$ ) acarretou benefícios no desempenho do reator (menor $\mathrm{DQO}_{\text {TOTAL }}$ e maior eficiência de remoção), possivelmente em decorrência de um melhor regime de mistura. Contudo, vale ressaltar que o baixo desempenho dos reatores no início da fase 4 (etapa 2) também pode estar associado à maior necessidade de adaptação da biomassa na transição entre as etapas 1 e 2 ao mudar o TDH de cinco para nove horas, bem como à perda de SSV no efluente (Figura 8), superior à fase 1, com as mesmas características operacionais;

- em condições desfavoráveis de operação (fase 3 - TDH de cinco horas e velocidade ascensional de $1,10 \mathrm{~m} / \mathrm{h}$ ), os efluentes apresentaram elevadas concentrações de $\mathrm{DQO}_{\text {TOTAL }}$ (Figura 4), com $75 \%$ dos resultados de eficiência de remoção abaixo de 50\% (Figura 5). Esse fato pode ser atribuído ao arraste de biomassa, ocasionado pela maior velocidade ascensional, já que a fração volátil dos SST nos efluentes, relacionada à perda de biomassa pelo sistema, foi muito elevada na fase 3 (Figura 8) e confirmada 


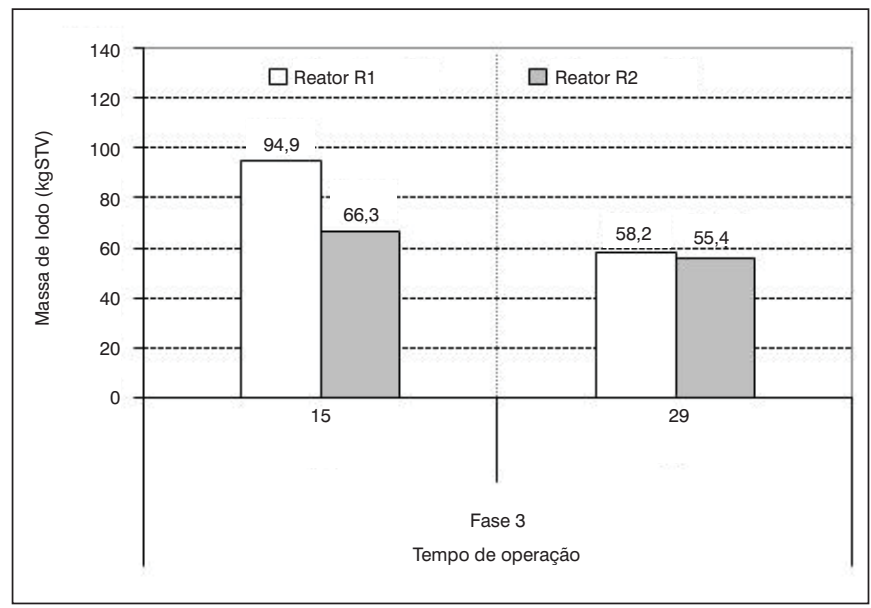

Figura 9 - Massa de lodo aferida na fase 3 dentro dos reatores controle (ER1) e precedido da UPF (ER2)

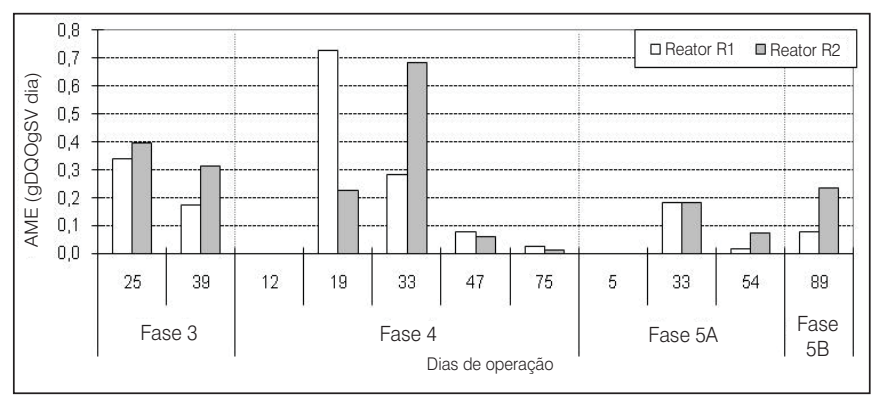

Figura 10 - Resultados dos testes de AME do lodo dos reatores

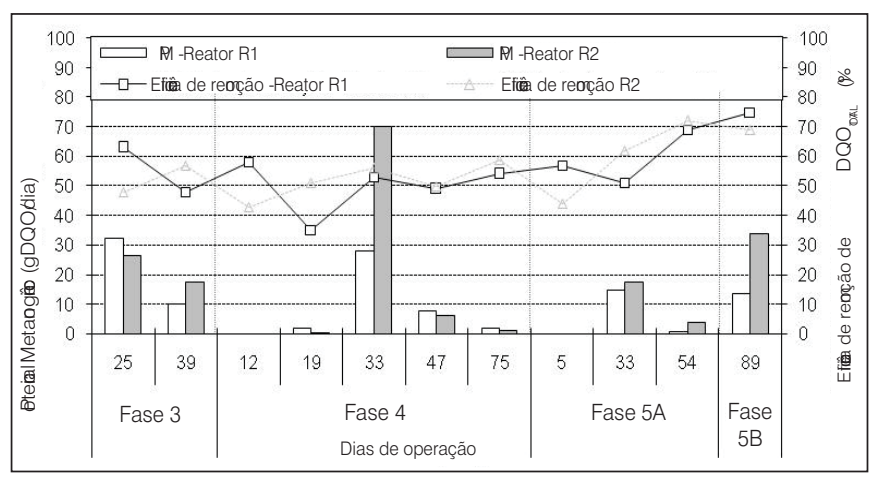

Figura 11 - Potencial Metanogênico do lodo e eficiência dos reatores

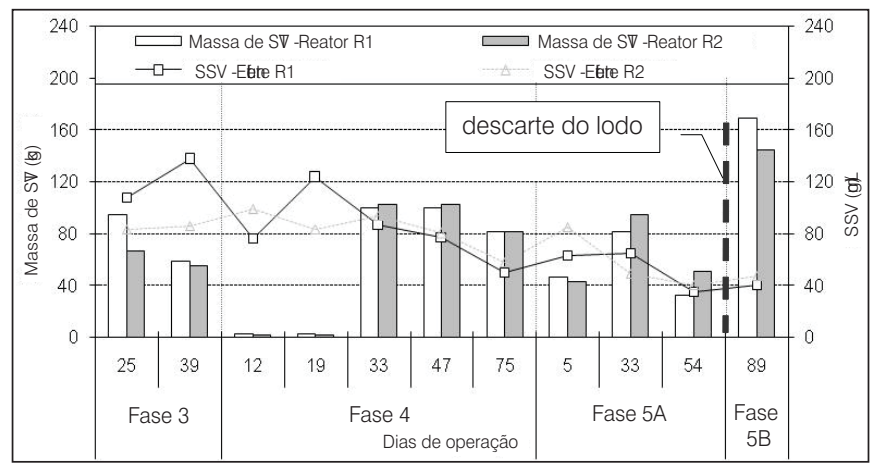

Figura 12 - Massa de STV dos reatores e concentração efluente de SSV pelos testes estatísticos. Contudo, as eficiências de remoção de $\mathrm{DQO}_{\text {FILTRADA }}$ se mantiveram elevadas ao longo do monitoramento realizado, como pode ser visto nas Figuras 6 e 7, e os testes de hipótese não apontaram diferenças relevantes.

Após análise da Figura 8 e considerando as condições hidrodinâmicas desfavoráveis da fase 3 , verifica-se que a concentração de SST e SSV no efluente do reator precedido da UPF é menor, constatação confirmada pelos testes $t$ de Wilcoxon. Isso pode ser um indicativo de seleção de biomassa com melhores características de sedimentabilidade, ocorrida durante as duas primeiras fases da pesquisa. Esse fato se confirma pela perda significativa de massa de lodo no reator controle (aproximadamente 39\%), enquanto, no reator precedido da UPF, a quantidade de STV no seu interior permaneceu muito próxima (Figura 9)

A Figura 10 apresenta os resultados obtidos pelos testes de AME realizados. Para auxiliar na discussão dos resultados, insere-se o conceito de Potencial Metanogênico (PM), que consiste em multiplicar o valor obtido no teste de AME pela massa de sólidos voláteis contida no reator. A Figura 11 apresenta os resultados do PM e a eficiência de remoção de $\mathrm{DQO}_{\text {TOTAL }}$ dos reatores, enquanto a Figura 12 mostra as condições do lodo (concentração de STV) aferidas nos reatores e a concentração efluente de SSV. Vale destacar que as condições dos testes de AME são diferenciadas das condições dos reatores, principalmente quanto à temperatura e substrato, o que implica ressalvas quando comparados os resultados do teste de AME aos dados obtidos na operação dos reatores.

$\mathrm{Na}$ fase 3, cujas condições operacionais não eram favoráveis (baixo TDH e elevada velocidade ascensional), o reator precedido da UPF apresentou maior AME, comprovada pelos testes estatísticos. Como o reator apresentava menor quantidade de STV, conclui-se que a manta de lodo do reator precedido da UPF era constituída, em sua maioria, por biomassa de maior atividade e menor quantidade de sólidos orgânicos. Consequentemente, o Potencial Metanogênico do reator R2 (17,3 g DQO/dia) foi superior ao do reator controle (10,2 g DQO/dia) no final da fase. Esses resultados refletiram-se no desempenho dos reatores, que apresentaram eficiência de remoção de $\mathrm{DQO}_{\text {TOTAL }}$ de 57 e $48 \%$ para o reator precedido da UPF e reator controle, respectivamente.

Com o período de transição entre as fases 3 e 4, a AME detectada no dia 12 foi nula, indicando a readaptação da biomassa a começar pelos organismos hidrolíticos e acidogênicos. Como a quantidade de lodo inoculada nos reatores na fase 4 foi muito pequena (de 2,3 e $1,2 \mathrm{~kg}$ STV, para os reatores controle e precedido da UPF, respectivamente), inferior ao mínimo requerido de aproximadamente $37 \mathrm{~kg}$ STV, observa-se que, após o período de readaptação das arqueias metanogências, houve um expressivo aumento da atividade metanogênica. Vale ressaltar que a estabilidade dos reatores foi mantida, mesmo quando apresentada menor massa de lodo (baixa concentração de 
STV), devido à elevada atividade metabólica da biomassa, retratando a resistência do lodo anaeróbio a elevadas cargas orgânicas.

No $19^{\circ}$ dia da fase 4 , o reator controle apresentou AME de $0,73 \mathrm{~g}$ DQO/g SV.dia, enquanto a AME do reator precedido da UPF foi de 0,23 g DQO/g SV.dia. Mesmo assim, a baixa concentração de STV nos reatores resultou em baixos valores de PM (1,7 e 0,3 g DQO/dia, para os reatores controle e precedido da UPF, respectivamente).

Já no $33^{\circ}$ dia de operação, o reator controle apresentou uma queda no valor aferido da AME, que passou a ser de 0,28 g DQO/g STV. dia, enquanto os resultados mostraram uma AME do reator precedido da UPF da ordem de 0,68 g DQO/g STV.dia. Como houve um crescimento considerável da quantidade de STV e a massa era de aproximadamente $100 \mathrm{~kg}$ STV em ambos os reatores (Figura 12), infere-se que a manta de lodo do reator R2 era constituída por uma biomassa com maior atividade, resultando, desse modo, em um PM bem superior ao do reator controle, como visto na Figura 11.

A partir de então ( $47^{\circ}$ dia), verificou-se uma queda representativa da AME dos dois reatores e, como a concentração de STV permaneceu a mesma, houve, consequentemente, uma baixa do PM da manta de lodo. Deduz-se, então, que após a readaptação da biomassa, começou a ocorrer o acúmulo de lodo inativo (sólidos orgânicos que não correspondem à biomassa), mostrando que, só então, a manta de lodo intensificou sua capacidade de retenção do material particulado afluente. A queda na concentração efluente de SSV a partir desse dia (Figura 10) confirma essa conclusão.

É interessante ressaltar que houve uma adaptação mais retardada do reator precedido da UPF. Talvez, a carga orgânica volumétrica aplicada (relação A/M) e o tamanho reduzido das partículas que adentram o reator tenham dificultado a adsorção do material particulado pela biomassa, prejudicando a degradação anaeróbia e, consequentemente, a disponibilidade de subprodutos necessários ao crescimento celular.

Vale lembrar que as fases 3 e 4 se caracterizaram, respectivamente, pela elevada carga hidráulica e biológica. O trabalho desenvolvido por Silva, Zerbini e Chernicharo (2007) caracterizou qualitativamente, durante as quatro primeiras fases da pesquisa (fases 1, 2, 3 e 4), as populações microbianas desses dois reatores por técnicas de biologia molecular (DGGE). Suas conclusões foram que as mudanças operacionais impostas aos reatores não alteraram a estrutura da comunidade de bactérias dentro do reator, o que indica uma estabilidade da biomassa como uma resposta adaptativa da comunidade bacteriana durante o tratamento do esgoto. Já Abreu (2007), analisando especificamente a comunidade de arqueias metanogênicas, observou leves flutuações populacionais nas fases 3 e 4 , sugerindo que algumas arqueias apresentaram maior atividade nestas fases.

De acordo com Liu e Tay (2004), reatores anaeróbios operados com alta velocidade ascensional e TDH reduzido exercem uma pressão seletiva sobre a comunidade microbiana. Além disso, elevada taxa de carga biológica aplicada durante a partida dos reatores mantém o crescimento microbiano sem que haja inanição da biomassa. Perante o exposto, é possível que tenha ocorrido uma seleção da comunidade microbiana nos reatores em estudo durante a fase 3; o aumento da relação A/M (em função da pequena quantidade inicial de biomassa nos reatores) imposto pela fase 4 na partida do sistema permitiu o desenvolvimento dessa biomassa selecionada.

Os trabalhos de Silva, Zerbini e Chernicharo (2007) e Abreu (2007) mostraram, no entanto, que a unidade de pré-tratamento não interferiu, aparentemente, no desenvolvimento da comunidade microbiana, apresentando resultados qualitativos semelhantes aos do reator controle.

No início da fase 5A, novamente, o lodo apresentou AME nula devido à sua readaptação às condições operacionais após o período de transição. Com um mês de operação, os reatores apresentaram AME semelhantes (aproximadamente 0,18 g DQO/g STV. dia), porém, uma maior concentração de lodo no reator precedido da UPF determinou um PM ligeiramente superior nesse reator (17,3 g DQO/dia contra 14,9 g DQO/dia). Após o descarte do lodo, a AME do reator precedido da UPF apresentou melhores resultados e também maior massa de STV, indicando que a população de micro-organismos que permaneceu no reator era possivelmente mais ativa do que no reator controle. Essas características da biomassa podem ter refletido no melhor desempenho do reator precedido da UPF, durante a fase $5 \mathrm{~A}$.

Com a inserção do meio suporte no compartimento de decantação (fase 5B), houve um aumento da AME. A AME do reator precedido da UPF $(0,23 \mathrm{~g}$ DQO/g STV.dia) foi bastante superior à do reator controle (0,08 g DQO/g STV.dia), não apresentando a mesma proporção em termos de massa de STV (144 e 169 kg STV, respectivamente). Com isso, o Potencial Metanogênico do reator controle foi inferior (13,6 g DQO/dia) ao do reator precedido da UPF (33,7 g DQO/dia). Todavia, a eficiência de remoção de $\mathrm{DQO}_{\text {TOTAL }}$ do reator controle foi melhor (75\%) do que a do reator precedido da UPF (69\%), provavelmente devido à maior capacidade de retenção física da biomassa no reator, proporcionada pela inserção do meio suporte.

Perante o exposto sobre a adaptação e seleção da biomassa à nova DTP da matéria orgânica do esgoto bruto e às bruscas alterações dos parâmetros hidrodinâmicos do reator ocorridas durante as quatro primeiras fases operacionais, infere-se que os resultados das fases $5 \mathrm{~A}$ e $5 \mathrm{~B}$ possam representar melhor as condições do sistema precedido da UPF, acrescido ao maior período de operação, como relatado.

Portanto, a discussão dos resultados da fase 5A mostram-se relevantes, podendo confirmar que a alteração da DTP do esgoto bruto, imposta pelo pré-tratamento, possa resultar em um melhor desempenho do reator UASB após seleção e desenvolvimento de uma biomassa com maior atividade. Além disso, a hibridização do reator, nesse caso, não beneficia sobremaneira a remoção de $\mathrm{DQO}_{\text {TOTAL }}$, como comprovada no reator controle, apenas diminuindo a perda de SST no efluente. 


\section{Conclusões}

O efeito da redução do tamanho de partículas, na faixa de 1,8 a $30 \mu \mathrm{m}$, parece ter favorecido o desenvolvimento e a seleção de uma comunidade microbiana com maior atividade metanogênica específica e a manutenção, no reator, de uma biomassa com maior potencial metanogênico. Todavia, tais constatações só foram confirmadas após a adaptação da biomassa às condições hidráulicas e cinéticas impostas.

Os benefícios do pré-tratamento com a UPF só foram comprovados estatisticamente quando o reator UASB foi operado com TDH de sete horas, velocidade ascensional de $0,50 \mathrm{~m} / \mathrm{h}$ e área de influência do tubo de distribuição igual a 2,25 m²/tubo. Para essa condição operacional, o reator precedido de UPF apresentou maior valor de AME (0,072 g DQO/g STV.dia, contra 0,018 g DQO/g STV.dia no reator controle), maior eficiência de remoção de $\mathrm{DQO}_{\text {TотAL }}$ (65 versus 54\% no reator controle) e menor concentração efluente de DQO ${ }_{\text {PARTICULADA }}$ (48 versus $74 \mathrm{mg} / \mathrm{L}$ no reator controle).

A hibridização do reator possibilitou o aumento da eficiência de remoção de $\mathrm{DQO}_{\text {TOTAL }}$ ( 71 versus 54\% no reator não hibridizado), a redução da concentração efluente de DQO $_{\text {PARTICULADA }}$ (40 versus 70 mg/L no reator não hibridizado) e também a redução da concentração efluente de SSV (24 versus 47 mg/L no reator não hibridizado). Todavia, tais benefícios não foram comprovados no reator precedido da UPF, uma vez que a fração particulada de DQO efluente e a eficiência de remoção de $\mathrm{DQO}_{\text {TOTAL }}$ foram semelhantes para essas duas condições.

\section{Agradecimentos}

Os autores agradecem aos órgãos fomentadores Financiadora de Estudos e Projetos (Finep) Programa de Pesquisas em Saneamento Básico (Prosab), Conselho Nacional de Desenvolvimento Científico e Tecnológico (CNPq) e Fundação de Amparo à Pesquisa do Estado de Minas Gerais (Fapemig), pelo financiamento da pesquisa, à Companhia de Saneamento de Minas Gerais (Copasa MG), pelo espaço cedido para implantação do aparato experimental, e à Prominas Brasil Equipamentos, por confeccionar e ceder gentilmente as peneiras metálicas utilizadas no estudo.

\section{Referências}

ABREU, E.F. Estudo da diversidade microbiana metanogênica em reatores UASB tratando esgoto sanitário. 81p. Dissertação. Departamento de Engenharia Sanitária e Ambiental da Escola de Engenharia da UFMG, Belo Horizonte, 2007.

AlYUK, S. et al. Anaerobic rand complementary treatment of domestic sewage in regions with hot climates: a review. Bioresource Technology, v. 97, n. 17, p. $2225-2241,2006$

AWWA/APHA/WEF. Standard methods for the examination of water and wastewater. $20^{\text {th }} \mathrm{ed}$. Washington, DC, 1998

ELMITWALLY, T.A. et al. Biodegradability and change of physical characteristics of particles during anaerobic digestion of domestic sewage. Water Research, v. 35, n. 5, p. 1311-1317, 2001.

LEVINE, A.D.; TCHOBANOGLOUS, G.; ASANO, T. Characterization of the size distribution of contaminants in wastewater: treatment and reuse implications. Journal Water Pollution Control Federation, v. 57, n. 7, p. 805-816, 1985.

LIU, Y.; TAY, J-H. State of the art of biogranulation technology for wastewater treatment. Biotechnology Advances, v. 22, n. 7, p. 533-563, 2004.
SILVA, S.Q.; ZERBINI, A.M.; CHERNICHARO, C.A.L. Diversidade microbiana em reatores UASB alimentados com esgoto sanitário e submetidos a diferentes condições operacionais. In: $24^{\circ}$ CONGRESSO BRASILEIRO DE ENGENHARIA SANITÁRIA E AMBIENTAL, Anais... Belo Horizonte, 2007.

TEIXEIRA, A.R. et al. Influência do peneiramento forçado do esgoto bruto no desempenho de reator UASB tratando esgoto doméstico. In: CONGRESSO BRASILEIRO DE ENGENHARIA SANITÁRIA E AMBIENTAL, 23, 2005, Campo Grande. Anais... Rio de Janeiro: Abes, 2005.

VAVILIN, V.A.; RYTOV, S.V.; LOKSHINA, L.Y.A. A description of hydrolysis kinetics in anaerobic degradation of particulate organic matter. Bioresearch Technology, v. 56, n. 2-3, p. 229-237, 1996.

VON SPERLING, M. Introdução à qualidade das águas e ao tratamento de esgotos. 3. ed. Belo Horizonte: UFMG, 2005. Princípios do tratamento biológico de águas residuárias, 1 .

WANG, K.; ZEEMAN, G.; LETTINGA, G. Alteration in sewage characteristics upon aging. Water Science Technology, v. 31, n. 7, p. 191-200, 1995 